\title{
Oxybutynin Chloride
}

National Cancer Institute

\section{Source}

National Cancer Institute. Oxybutynin Chloride. NCl Thesaurus. Code C73597.

The chloride salt form of oxybutynin, a tertiary amine and anticholinergic agent with antispasmodic activity. Oxybutynin chloride exerts its antimuscarinic effect on bladder smooth muscle by blocking muscarinic receptors in smooth muscle, thereby inhibiting acetylcholine binding. This results in a relaxation of bladder smooth muscle, a reduction of involuntary muscle contractions and delays the initial desire to void. 